\title{
Improvement of Energy Density in Single Stator Interior Permanent Magnet Using Double Stator Topology
}

\author{
Raja Nor Firdaus, ${ }^{1,2}$ Norhisam Misron, ${ }^{1,3}$ Chockalingam Aravind Vaithilingam, \\ Masami Nirei, ${ }^{5}$ and Hiroyuki Wakiwaka ${ }^{6}$ \\ ${ }^{1}$ Department of Electrical and Electronics, Faculty of Engineering, Universiti Putra Malaysia, Malaysia \\ ${ }^{2}$ Faculty of Electrical Engineering, Universiti Teknikal Malaysia, Melaka, Malaysia \\ ${ }^{3}$ Institute of Advanced Technology (ITMA), Universiti Putra Malaysia, 43400 Serdang, Selangor, Malaysia \\ ${ }^{4}$ CIARG, School of Engineering, Taylor's University, 47500 Selangor, Malaysia \\ ${ }^{5}$ Nagano National College of Technology, 716 Tokuma, Nagano 381-8550, Japan \\ ${ }^{6}$ Shinshu University, 500 Wakasato, Nagano 380-8553, Japan
}

Correspondence should be addressed to Norhisam Misron; norhisam@eng.upm.edu.my

Received 18 October 2013; Revised 15 March 2014; Accepted 21 March 2014; Published 23 April 2014

Academic Editor: Sergio Preidikman

Copyright (C) 2014 Raja Nor Firdaus et al. This is an open access article distributed under the Creative Commons Attribution License, which permits unrestricted use, distribution, and reproduction in any medium, provided the original work is properly cited.

\begin{abstract}
The paper presents the energy density improvement using magnetic circuit analysis of the interior permanent magnet motor. The leakage flux from the conventional structure is improved with modified magnetic circuit to improve the energy and thereby the torque value. This is approached with a double stator structure design. The proposed structure is investigated with two design variations, namely, the double stator with thin pole shoe and the double stator with thick pole shoe motors. Variations in the mechanical parameters of the all the developed models are analyzed through the finite element analysis tool. In all investigations the magnetic source is fixed in both the permanent magnet volume and coil magnetomotive force, respectively, as $400 \mathrm{~mm}^{3}$ per each pole and 480 Ampere turns per pole. From the analysis the best fit magnetic structure based on the torque characteristics is derived and is fabricated for the same volume as that of the conventional structure for performance evaluations. It is found out that there is improvement on the motor constant square density for the proposed improved magnetic circuit through the best fit double stator with thick pole shoe by about $83.66 \%$ greater than that of the conventional structure.
\end{abstract}

\section{Introduction}

Single phase interior permanent magnet (IPM) motors are adopted in many low cost applications such as in fan, blowers, and other domestic appliances [1-5]. The main disadvantage of using single phase compared to three-phase permanent magnet motor is its inability to self-start [6-8]. However, for specific application such as the mechanical chopper, the single phase motor is the most popular application due to the safety consideration. The requirement for such type of motor is of high torque with low cogging torque values. A high torque performance motor usually comes with high cogging characteristic that introduces torque ripple inside the motor. A pure sinusoidal torque characteristic ensures uniform flux distribution that produce smooth speed rotation with negligible torque ripple [9-12]. The cogging torque is caused by the variation of the magnetic energy of the field due to the interaction of permanent magnet (PM) and the slot under the mechanical angular position of the rotor [13-15]. There are many possible ways to reduce cogging torque such as skewing, optimizing, or varying the magnet pole arc width and introduction of dummy slots $[16,17]$. However, each of them gives significant variations in the output torque value. The increase in magnetic energy significantly increases the torque value that is realized by resizing the volume of the magnet or with introduction of larger number of coil turn [18-20]. However, the flux density in some parts of stator or rotor of permanent magnet motor is increased leading to saturation value as the volume of magnet is increased. At this saturation point, the magnetic energy no longer contributes 
to torque generation and is considered as air gap that is highly ineffective. Therefore, study on ways to optimize the magnetic energy flow perpendicular to the air gap surface inside a permanent magnet motor is to be investigated at the first stage. An optimal air gap magnetic energy with reduction of cogging torque value is realized through a sinusoidal torque waveform. Then, the process of resizing the PM volume or adding the number of coil turn is used to estimate the performance limit of the desired motor.

This paper presents the analysis on the magnetic circuit design of single stator and double stator and the improvement in the magnetic energy of the double stator with magnetic circuit design. Analysis on the variations of the mechanical parameter that changes the optimal magnetic energy in the air gap that contributes to the generation of torque characteristics of the all structures is presented. Finite element analysis (FEA) is used as a numerical tool to derive the torque characteristics based on various combinations of taper parameters. The analysis result shows that minimum value of total harmonic distortion (THD) is found by optimizing the dimensions of the width of slot and that of the rotor. Also it is found that with reducing height of stator teeth a symmetrical torque waveform is evolved. The analysis is evaluated based on the value of the minimum total harmonic distortion (THD), the maximum fundamental torque $T_{f}$, the maximum peak torque $T_{p}$, and the minimum cogging torque $T_{c}$. For comparative evaluations, the motor constant square density $(G)$ is used. The model of improved series magnetic circuit is fabricated and tested experimentally. The comparison result shows that measurement results have good agreement with the simulation result.

\section{Machine Design and Magnetic Circuit Design Analysis}

2.1. Single Stator Structure. Figure 1 shows the typical single stator interior permanent magnet (SSIPM) [16-20]. In this research, the 6-pole 6-slot configuration of permanent magnet motor is considered. This is due to the specific application that requires both torque and speed for portable mechanical chopper used in agricultural sector. The overall diameter of the permanent magnet motor is set for $55 \mathrm{~mm}$ with $5 \mathrm{~mm}$ diameter of shaft. The permanent magnet is made from $\mathrm{NdFeB}$ grade of 42 with a dimension of $4 \mathrm{~mm}$ of width and $5 \mathrm{~mm}$ of height. The technical property of the permanent magnet is shown in Table 1. The shaft is made from nonmagnetic steel (SUS304). The rotor and stator are made up of standard silicon steel known as JI: $50 \mathrm{H} 800$. The stack length and the air gap length between stator and rotor are set for $20 \mathrm{~mm}$ and $0.1 \mathrm{~mm}$, respectively.

It comprises of a stationary stator and the rotational rotor that moves to develop the torque. With variety in design structure available in the literature, the above structure shows the conventional design with an outside stationary rotor and an inside cylindrical rotor coupled to the output shaft. The stator comprises of set of energised copper coils in succession to generate the magnetic flux. The stator flux interacts with the rotor, which is mounted inside the rotor in such a way
TABLE 1: Parameters varied in this investigation.

\begin{tabular}{lc}
\hline Property & Values \\
\hline Remanent flux density, $B_{r}[\mathrm{~T}]$ & $1.28-1.32$ \\
Coercivity, $H_{c}[\mathrm{kA} / \mathrm{m}]$ & $>923$ \\
Intrinsic coercivity, $i H_{c}[\mathrm{kA} / \mathrm{m}]$ & $>955$ \\
$\mathrm{BH}$ max, $\mathrm{kJ} / \mathrm{m}^{3}$ & $318-342$ \\
Operating temperature, $T$ & $20^{\circ} \mathrm{C}$ to $120^{\circ} \mathrm{C}$ \\
\hline
\end{tabular}

that it can turn to align itself with the fields generated by the coils. This full alignment force generates torque, turning the rotor so that it moves the load through the shaft.

\subsection{Magnetic Circuit Analysis of Single Stator Structure.}

Figure 2 shows single stator interior permanent magnet (SSIPM) motor type that forms two parallel magnetic circuits: one magnetic circuit is enclosed by stator and coils while the other magnetic circuit is in the rotor side. However, only magnetic circuit in the stator side is involved in the torque generation process as it consists of air gap where by the force is developed in this region. In this magnetic circuit, it has much reluctance as the flux is surpassing from the permanent magnet to the stator and coming back to its origin point. The reluctances in other magnetic circuit which are $2 R_{\mathrm{rp} 1}, 2 R_{\mathrm{rp} 2}$, and $R_{\mathrm{rp} 3}$ unused as the magnetic energy of the permanent magnet is been divided (reluctance torque) and not being used for torque production. The net reluctance in the magnetic circuit is given as

$$
R=\left[R_{\text {osy }}+2\left(R_{\mathrm{sps}}+R_{\mathrm{sp}}\right)+2\left(R_{\mathrm{rp}}\right)+2 R_{\mathrm{ag}}\right] .
$$

The reluctance torque $R_{r}$ in the rotor circuit that is unused is given as follows:

$$
R_{r}=\left[2 R_{\mathrm{rp} 1}+2 R_{\mathrm{rp} 2}+R_{\mathrm{rp} 3}\right]
$$

is unused as there is no useful energy produced in the circuit. In other words, if the unused leakage flux in the air gap is effectively utilized through another magnetic circuit, then the torque density can be improved.

2.3. Magnetic Circuit Design Concept. The motivation on the introduction of magnetic circuit in the rotor part of the single stator interior permanent magnet (SSIPM) structure is proposed in this section. The design improvements in the magnetic circuit are highly influenced by the property of the material that is involved in the energy conversion process and also the effective area of energy conversion. From the first principles of magnetism, the reluctance in a magnetic circuit is given as

$$
R=\frac{l_{g}}{\mu A_{g}},
$$

where " $R$ " is the reluctance value for the length of the energy conversion contact surface and " $A_{g}$ " is the area of cross section of the contact surface. Ideally the variations in the length of the magnetic flux flow and the variations in the 


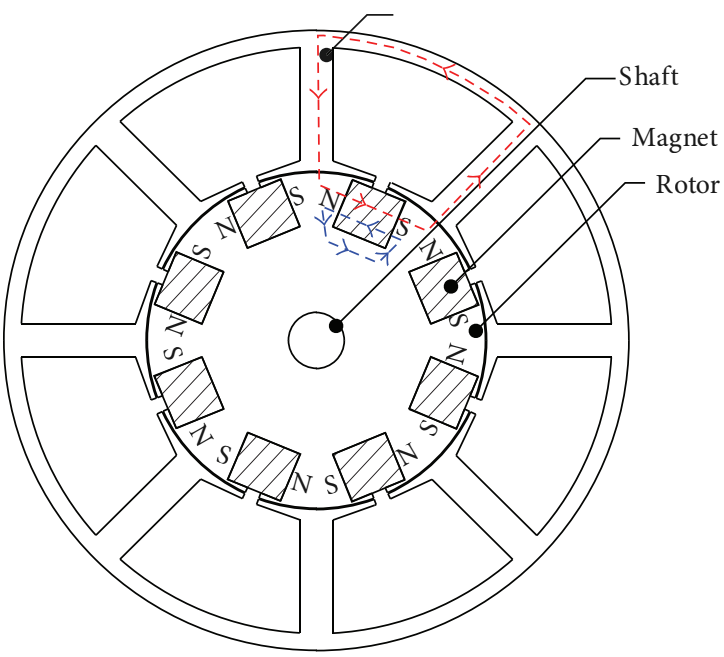

(a)

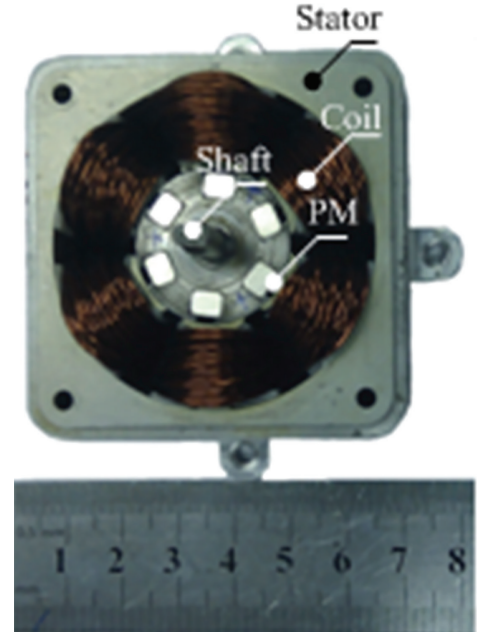

(b)

FIgURE 1: Conventional SSIPM. (a) Structural configurations; (b) fabricated SSIPM motor.

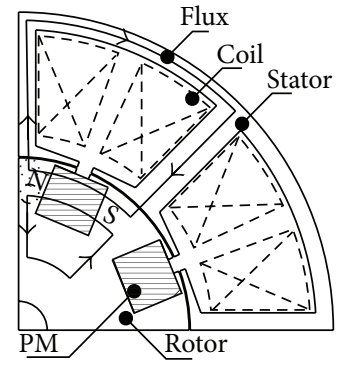

Magnetic torque $T_{m}$ $\therefore$ Reluctance torque $T_{r}$

(a)

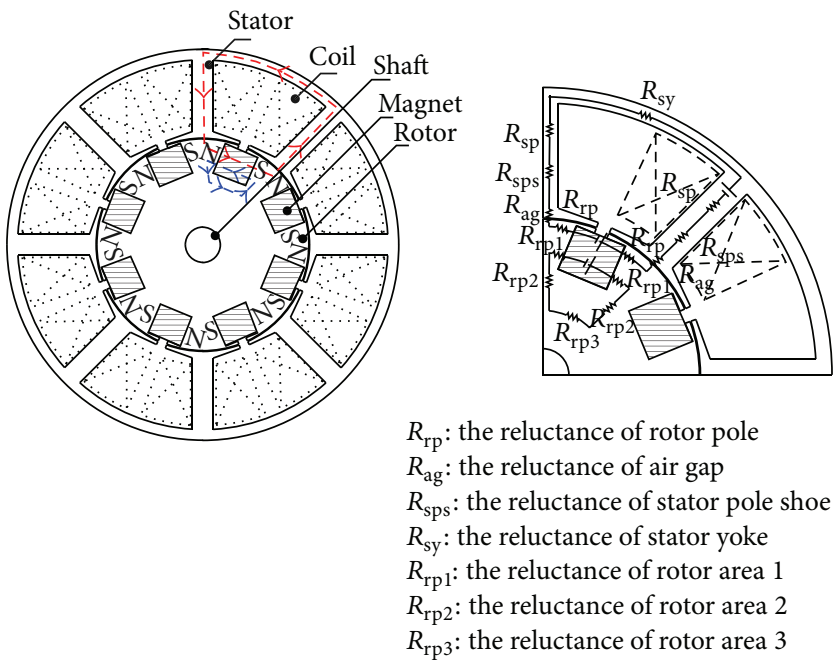

(b)

FIgURE 2: Magnetic circuit analysis of the SSIPM. (a) Magnetic flux flow path; (b) equivalent magnetic circuit flow.

contact area between the parts of the magnetic circuit would heavily influence the net magnetic circuit values and thereby the torque density value of the machine. In a magnetic circuit with the air gap $l_{g}>0$, most of the MMF is expended on the air gap and most of the energy is stored in the air gap with its volume $A_{g} l_{g}$, where $A_{g}$ is the cross section area of the air gap. The energy per volume is given as

$$
w=\frac{W}{A_{g} l_{g}}=\frac{1}{2} B_{g} H=\frac{1}{2} \frac{B_{g}^{2}}{\mu_{0}},
$$

where $B_{g}=\mu_{0} H=\mu_{0}(N i / z), z=l_{g}$, and $i$ is the instantaneous electric current. Therefore the energy in the reluctance torque produced surface is given as

$$
W=\frac{\mu_{0}(N i)^{2}}{l_{g}} A_{g} .
$$

The reluctance magnetic circuit from the conventional single stator structure is converted to dual magnetic circuit using the double stator topology wherein the field magnetomotive force $(\mathrm{mmf})$ is established through coil $(\mathrm{Ni})$; the air gap introduces the air-gap section area and length. This evolves in the dual magnetic circuit, namely, outer stator magnetic circuit and the inner stator magnetic circuit. In this way the unused magnetic circuit in the inner rotor is converted in another magnetic circuit that helps to improve the torque generation in the air gap contact surface. This structure with double stator magnetic circuit is referred to as double stator IPM (DSIPM). The approach on introduction of dual magnetic circuit to increase energy density is proposed for switched reluctance motor (SRM) in $[21,22]$ and also for brushless DC motor (BLDC) in [23]. 

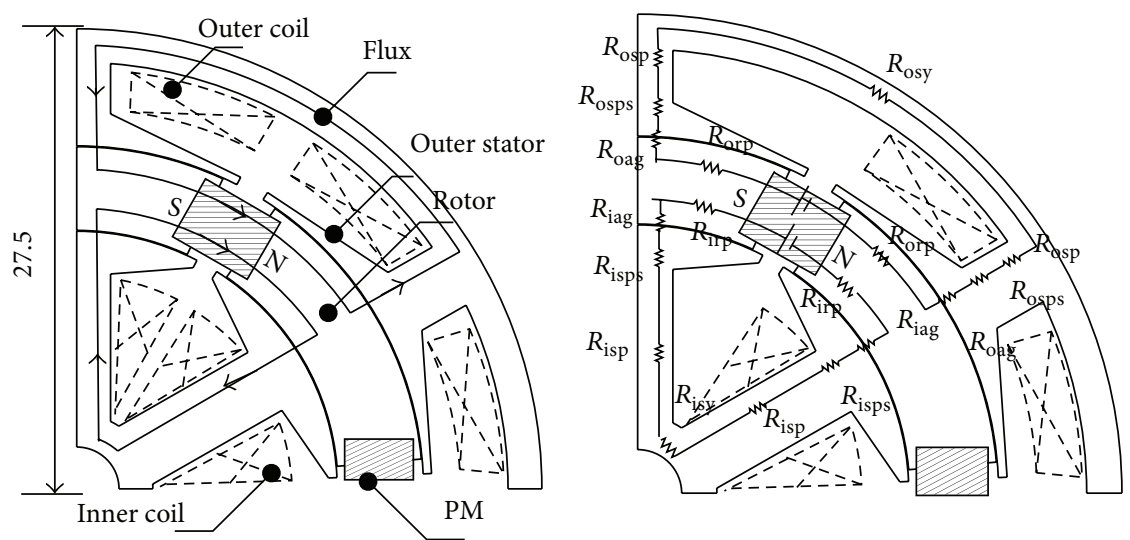

$R_{\text {osps }}:$ the reluctance of outer stator pole shoe

$R_{\text {isps }}$ : the reluctance of inner stator pole shoe

$R_{\text {oag }}$ : the reluctance of outer rotor air gap

$R_{\text {iag }}$ : the reluctance of inner rotor air gap

$R_{\text {isy }}$ : the reluctance of inner stator yoke

$R_{\text {osy }}$ : the reluctance of outer stator yoke

$R_{\text {isp }}$ : the reluctance of inner stator pole

$R_{\mathrm{osp}}$ : the reluctance of outer stator pole

$R_{\text {irp }}$ : the reluctance of inner rotor

$R_{\text {orp }}$ : the reluctance of outer rotor

FIgURE 3: Magnetic circuit analysis of the DSIPM. (a) Magnetic flux flow path; (b) equivalent magnetic circuit flow.

\subsection{Double Stator Interior Permanent Magnet (DSIPM)} Machine. The rotor leakage flux from the SSIPM is catered with the introduction of another stator structure inside the machine, known as double stator interior permanent magnet (DSIPM) motor. It has two stators known as an outer and inner stator. Theoretically, this two magnetic circuits arrangement provides higher torque production compared to single stator since two air gaps are provided in between stator and rotor. Based on the magnetic equivalent circuit of this model, the flux has to go through $2 R_{\text {osp }}, 2 R_{\text {osps }}, 2 R_{\text {orp }}$, and $R_{\text {osy }}$ for outer stator side magnetic circuit. In the inner stator side magnetic circuit the flux has to go through $2 R_{\text {isp }}, 2 R_{\text {isps }}, 2 R_{\text {irp }}$,

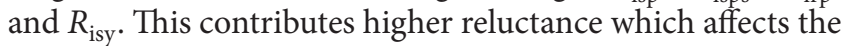
flux through any cross section of a magnetic circuit. The feature that includes the additional stator is introduced in the rotor side known as double stator, with parallel magnetic circuit topology (Figure 3). The resultant magnetic circuit of the DSIPM (only for one sector of energy conversion) of magnetic circuit is as given by

$$
\begin{aligned}
R=\left[R_{\text {osy }}+2\left(R_{\text {sps }}+R_{\text {sp }}\right)+2\left(R_{\text {orp }}\right)+2 R_{\mathrm{ag}}\right] \\
\|\left[R_{\text {isy }}+2\left(R_{\text {sps }}+R_{\text {sp }}\right)+2\left(R_{\text {orp }}\right)+2 R_{\text {ag }}\right] .
\end{aligned}
$$

2.5. Magnetic Circuit Improvements. However, there is a large area of ferromagnetic material on the rotor part that affects the flux through any cross section of rotor magnetic circuit. The value of $R_{\text {orp }}$ and $R_{\text {ag }}$ is critical in developing the torque density as it is the point at which the effective magnetic energy and the electromagnetic energy interacts to develop the torque. By the variations of the mechanical parameter at this point contact the energy density is improved. The effect of the converging area at the point of contact (between the magnet and the stator) is improved with the use of pole shoe. Further to the conversion of the DSIPM of parallel magnetic circuit to series magnetic circuit by changing the orientation of the magnet. The introduction of the pole shoe divides the flux path in the magnetic circuit introducing reluctance components. The variations of the reluctance components are investigated through the variations in their height and width. Further the size ratio of the magnet influences the torque density due to the orientation of the magnetic grains inside the machine.

This variation in the magnet in this investigation is classified to be of the DSIPM with thin pole shoe and DSIPM with thick pole shoe. The resultant magnetic circuit reluctance value is as shown in

$$
\begin{aligned}
R= & {\left[R_{\text {osy }}+4\left(R_{\text {sps }}+R_{\text {sp }}\right)+2\left(R_{\text {orp }}\right)+4 R_{\mathrm{ag}}\right] } \\
& +\left[R_{\text {isy }}+2\left(R_{\text {irp }}\right)\right] .
\end{aligned}
$$

Based on DSIPM, there is a large area of ferromagnetic material on the rotor part. The higher reluctance allows flux leakage to occur at inner air gap which contributes to negative torque production. Therefore, this ferromagnetic material area must be decreased. To address this negative effect the magnetic circuit is enhanced with the introduction of pole shoes in the magnet surfaces. Two different types of magnetic structure are analyzed, namely, DSIPM with thin pole shoe and DSIPM with thick pole shoe. As seen in this structure the optimal magnetic energy in the air gap is affected by the permanent magnet area encapsulated. With varying the 


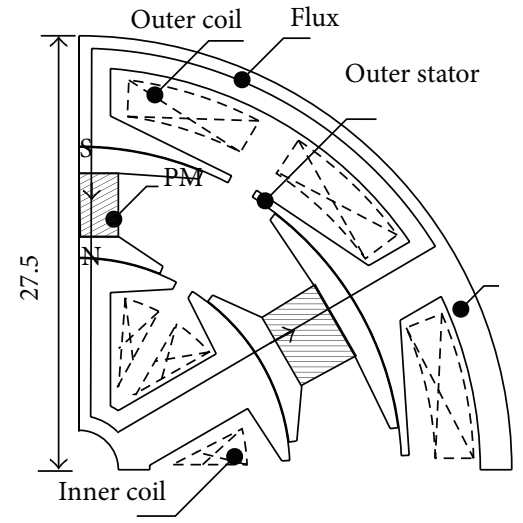

(a)

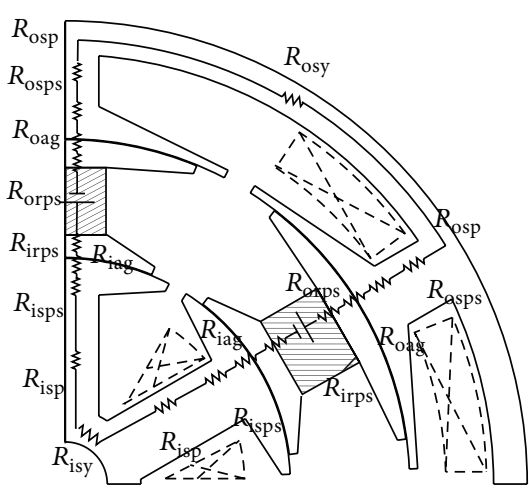

(b)

FIGURE 4: Magnetic circuit analysis of the DSIPM with thin pole shoe. (a) Magnetic flux flow path; (b) equivalent magnetic circuit flow.

ration of width to height values but keeping the net volume of magnet fixed $400 \mathrm{~mm}^{3}$ volume, the DSIPM with thick pole shoe is evolved. This increases the effective area between permanent magnet and pole shoe. As can be seen in both pole shoe structures the magnetic circuit is serial in nature and hence the torque density is expected to improvise compared to the parallel circuit of the double stator IPM structure.

\subsubsection{Double Stator Thin Pole Shoe Configurations (DSIPM} with Thin Pole Shoe). The features of the double stator thin pole shoe configurations with series magnetic circuit topology include the influence on the magnetic energy in the air gap that is affected by the permanent magnet area. The magnetic energy in the air gap can be improvised by having thinner pole shoe to reduce the reluctance torque value (Figure 4).

\subsubsection{Double Stator Thick Pole Shoe Configurations (DSIPM} with Thick Pole Shoe). In this configuration with the series magnetic circuit, the permanent magnet width and height values are interchanged with fixed magnet volume to increase the effective area between permanent magnet and pole shoe. The magnetic energy improvement in the airgap can be achieved with the introduction of thinner magnet and increasing the pole shoe contact area (Figure 5).

The additional air gap reluctance between the stator and rotor influence the improvement in the torque density values. However the design has to be optimized in order to minimize the effect of radial pull. Also the construction of this type of structures using the double stator topology is quite challenging. The analysis of the proposed magnetic circuit by the variations in the various mechanical parameters is essential to have a comprehensive analysis of the results. The parameters used in this investigations include the width of outer stator $\left(W_{\mathrm{os}}{ }^{\circ}\right)$, width of inner stator $\left(W_{\mathrm{is}}{ }^{\circ}\right)$, width of outer rotor $\left(W_{\text {or }}^{\circ}\right)$, width of inner rotor $\left(W_{\text {ir }}^{\circ}\right)$, height of outer stator pole teeth $\left(H_{\text {ospt }}\right)$, height of inner stator pole teeth $\left(H_{\text {ispt }}\right)$, and height of rotor teeth $\left(H_{\text {rth }}\right)$. For simplification, a ratio is known as ratio of slot and pole width $\left(W_{s}^{\circ}-W_{r}^{\circ}\right)$ that shows the effect of air gap area between the stator and rotor width is used in the investigations. All of the proposed magnetic circuit is constructed using standard finite element tool as described in the next section in brief.

\section{Numerical Analysis}

3.1. Finite Element Method. In order to facilitate the torque characteristics of single phase DC permanent magnet motor based on the magnetic circuit design finite element analysis (FEA) is employed to predict the magnetic distribution. Finite element analysis (FEA) is used to compute the magnetic characteristics, but this necessitates a package and more time for modeling the motor and is used extensively by researchers in machine design. Most of them use computational tools to demonstrate the first hand information on the property of the machine [18-20]. The FEA tool used in this investigation is developed based on the nodal force method [24]. This method is similar to the method of finding equivalent nodal force from distributed load force in stress analysis. The magnetic volume and the surface forces are through the Maxwell stress tensor using the Einstein's summation convention. For any three-dimensional volume of boundary surface, $T_{i k}$ is the stress tensor and $n$ is the unit vector from region 1 to region 2 perpendicular to the surface; then the Maxwell stress tensor is given by

$$
T_{i k}=H_{i} B_{k}-\delta_{i k} \rho_{c o},
$$

where $\delta$ is the Kronecker's delta (here $\rho_{c o}$ is a piecewise function of variables $i$ and $k$ with the value being 1 when $i=k$; else it is zero) and the coenergy density is given in

$$
\rho_{c o}=\int_{0}^{H} B d H .
$$

In FEM calculations that use the Maxwell method alone, the discontinuity occurs due to the interpolation functions at the element interfaces.

The nodal force $f_{n i}$ is then given as

$$
f_{n i}=\left(-\int T_{i k} \delta_{k} w_{n}\right) d \nabla
$$




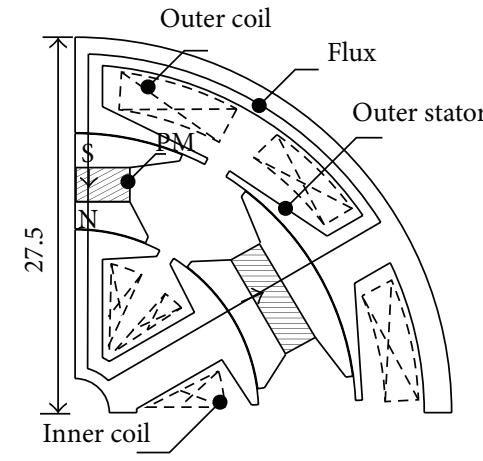

(a)

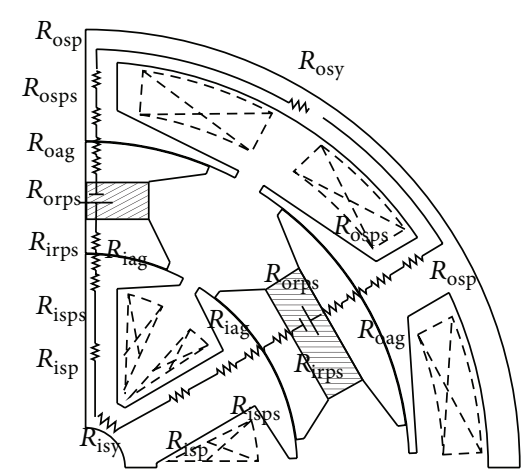

(b)

FIGURE 5: Magnetic circuit analysis of the DSIPM with thick pole shoe. (a) Magnetic flux flow path; (b) equivalent magnetic circuit flow.

In the above equation the integration is over the elements that connect the nodes in the design. The virtual displacement for the work done by the magnetic force is given as

$$
\delta W=\sum_{n}\left(-\int T_{i k} \delta_{k} w_{n} d \nabla\right) \delta_{n i},
$$

where $w_{n}$ is the nodal shape function and $\delta_{n i}$ is the virtual nodal displacement. With no spatial differentiation of the field quantities of $B, H$ is needed and the discontinuity of the calculated field causes no difficulties; the resultant force is calculated by summation of the nodal forces at various nodes in the body. The formulation does not depend on the interpolation functions as used in other FEA tools. Hence the results originated from this FEA tool are highly accurate even though the computation calculation is heavier.

3.2. Design Formulations. Figure 6(a) shows the meshing constructed for the analysis of the IPM structure. In order to make the FEM calculations more accurate there are six circular tubes that are constructed in the programming design in both the two air gap surfaces as in Figure 6(b). The design sequence in the programming of the FEA in this investigation is as in Figure 7. It involves three stages; the first one is the development of model based on the design parameters and the setting of the mesh points and the configuration settings including the number of turns and the impressed current. The second stage is the computations of the designed model. The third stage is to derive the magnetic and mechanical values from the computations results. Both extraction and analysis for the machine performance are used by mathematical tool software. The automatic variations on the parameter can be set in the analysis and hence the computation is relatively easier once the basic mechanical structure is constructed using the FEA programming tool. The model used mesh generators that construct using Delaunay triangulation method. This self-adapting mesh relies on an accurate and reliable method of estimating the discretization error in the mesh. The mesh accuracy can be controlled by the user accordingly in the finite element calculation. The air gap of model has been divided up to six layers of meshes and the modeling of each geometry developed according to the parameter changes.
This has reduced the calculation time and provides accurate simulation result.

3.3. Design Evaluations. The torque characteristic of interior permanent magnet motor is compared through values of maximum torque $\left(T_{m}\right)$, cogging torque $\left(T_{c}\right)$, fundamental torque $\left(T_{f}\right)$, and total harmonic distortion (THD). $T_{m}$ can be described as the peak of torque waveform. In this research, $T_{m}$ is the actual torque that is calculated from FEA. The $T_{m}$ is not a direct indication of the torque characteristics to exhibit a high component value of torque. $T_{c}$ is the torque generated due to the interaction between the permanent magnet of the rotor and the stator. $T_{c}$ is an undesirable component for the operation of a motor. In this research, $c$ is an actual torque that is calculated from FEA.

$T_{f}$ can be described as the fundamental harmonic of the torque waveform calculated by fast Fourier transform (FFT) analysis. The fundamental torque presents the component of sinusoidal torque waveform in the torque characteristics. This means that higher value of fundamental torque develop higher torque component in the torque waveform. Based on the simulation result of torque for every combination taper parameter of each magnetic circuit, lists of torque characteristics are developed. From the torque characteristic itself, four components known as the total harmonic distortion (THD), fundamental torque $T_{f}$, the maximum torque $T_{m}$, and cogging torque $T_{c}$ are determined. From this overall data, selection is made based on minimum total harmonic distortion (min. THD), maximum fundamental torque (max. $T_{f}$ ), maximum torque ( $\max . T_{m}$ ), and minimum cogging torque $\left(\min . T_{c}\right)$. These four types of evaluation selection show different perspective of torque characteristics. The evaluation selection based on $\mathrm{min}$. THD indicates the best torque waveform that near to sinusoidal shape. The evaluation based on selection of max. $T_{f}$ shows higher torque component among all the models. The evaluation based on max. $T_{m}$ indicates a model with the highest peak of torque from the overall model. Lastly, evaluation based on minimum cogging torque min. $T_{c}$ indicated a model that has the lowest cogging torque from the overall model. Figure 8 shows evaluation methodology used in evolution of the best fit magnetic circuit for the IPM motor. 


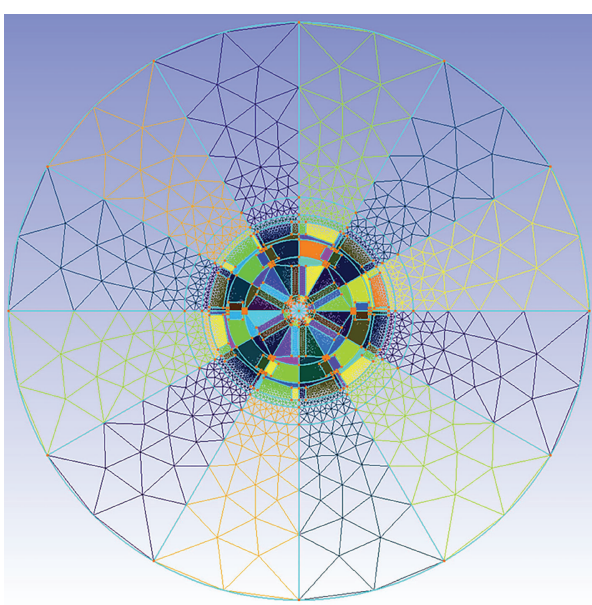

(a)

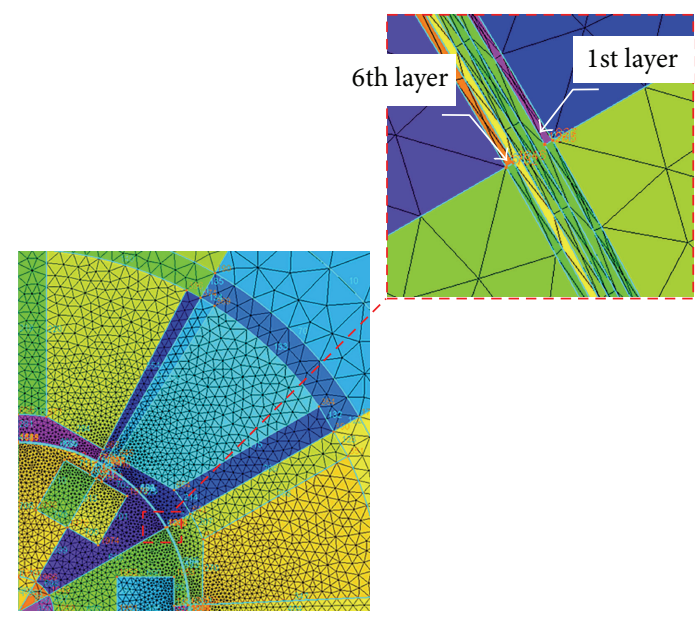

(b)

FIgure 6: Mesh setting inside the FEA. (a) Mesh of the design; (b) six layers of mesh in the air gap set for FEA.

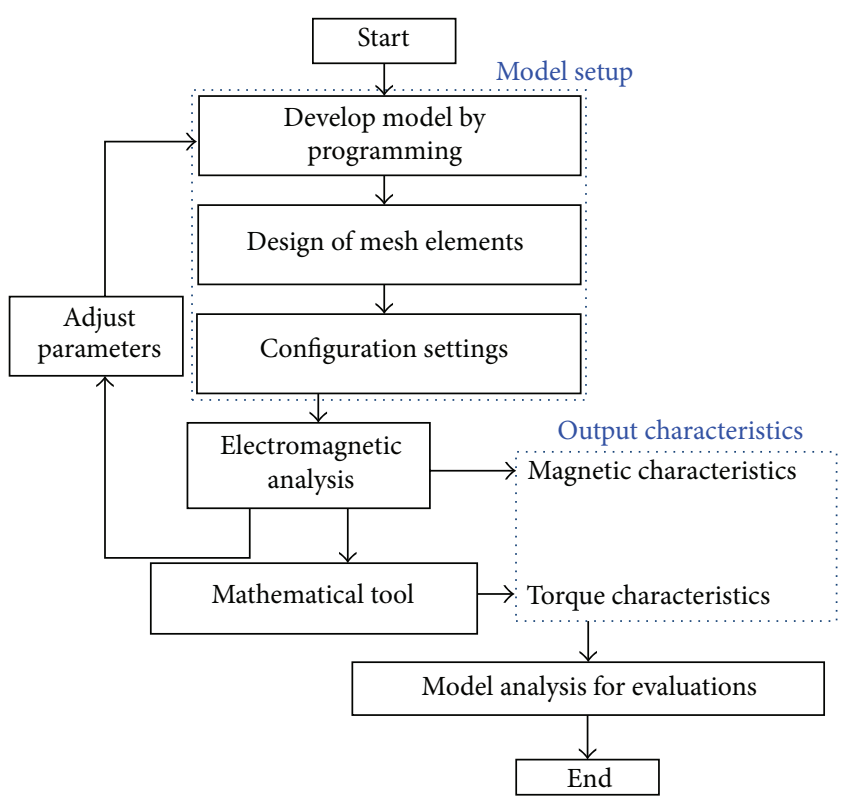

Figure 7: Magnetic circuit analysis using FEA.

3.4. Analysis Parameters. Table 2 shows the various parameters used in the analysis. As instance for the case of the SSIPM type motor can be seen for each of the ratio the stator to rotor width $\left(W_{s}^{\circ}-W_{r}^{\circ}\right)$ the taper height $\left(H_{\mathrm{spt}}\right)$ is varied. In this design the maximum swept angle for the analysis is $60^{\circ}$ and with a clearance of $6^{\circ}$ the possible ratio of $\left(W_{s}^{\circ}-W_{r}^{\circ}\right)$ is analysed for other parameters as shown in Table 3.

The double stator topology involves two taper parameters, namely, outer stator taper $\left(H_{\text {ospt }}\right)$ and inner stator taper $\left(L_{\text {ospt }}\right)$. Hence for the same ratio values of stator to rotor width value the tapers are varied and the values are plotted. Based on the overall analysis data of taper parameter, an evaluation is proposed to select the best possible fit from the various possible combination values. The method is to plot all data in single graph based on the ratio of slot and pole width as the taper height is varied. Table 3 shows the taper parameters used in the single stator and double stator topology.

\section{Results and Discussions}

4.1. Numerical Result Analysis. For each of the combinations from Table 3 the values of $T_{m}, T_{c}, T_{f}$, and THD for the single and double stator topology are investigated and are plotted as in Table 4. From the values plotted result the analysis is done based on the min. THD, max. $T_{f}$, max. $T_{m}$, and min. $T_{c}$ values. The analysis motivated in the evaluation of the proper evaluation strategy is used in selecting the best fit of permanent magnet motor. The individual computed values from the Table 4 is plotted and evaluation condition (as shown in the redline) is used to choose the best of the 


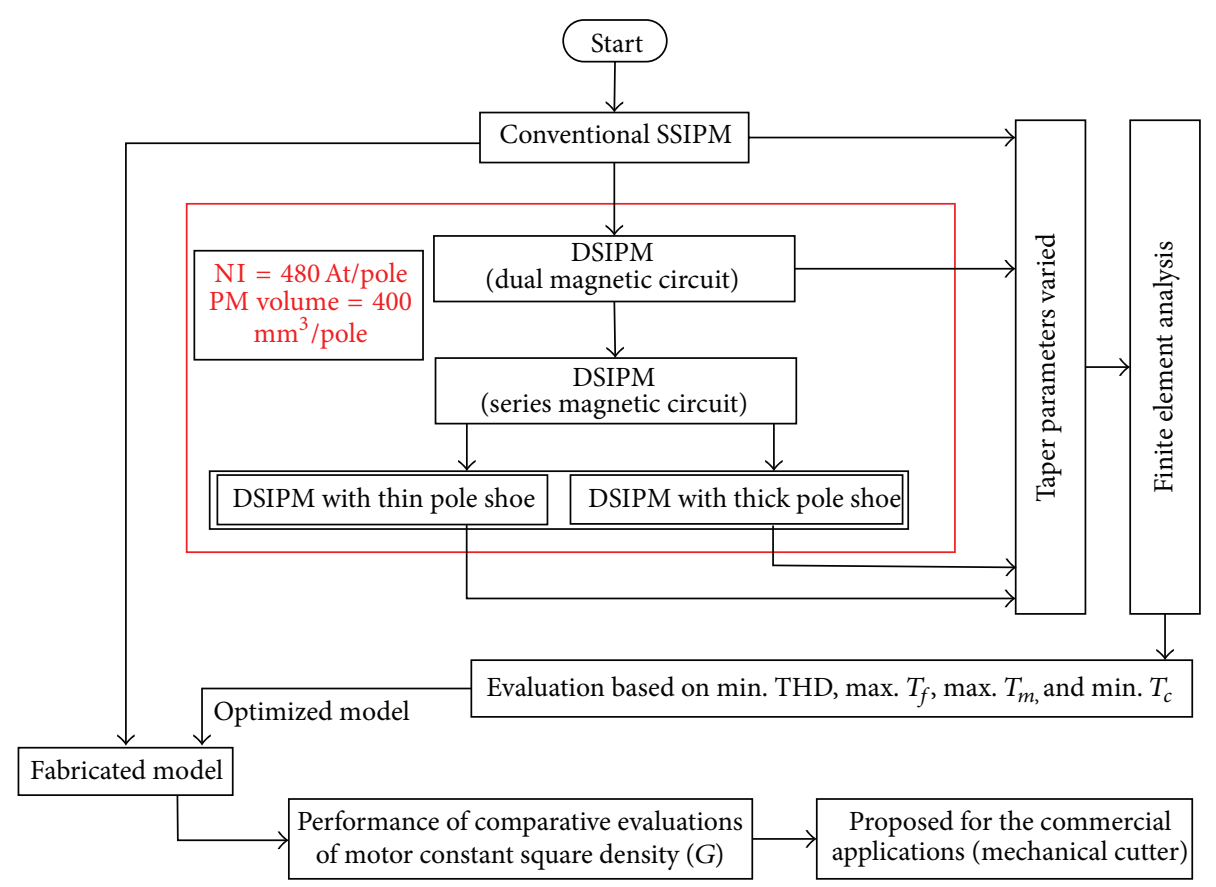

FIgURE 8: Methodology in the magnetic circuit evaluation strategy.

TABLE 2: Parameters varied in this investigation.

SSIPM DSIPM DSIPM with thick pole shoe

TABLE 3: Values of taper parameters used in the simulation.

\begin{tabular}{lcrr}
\hline & Single stator topology (SSIPM) & \multicolumn{2}{c}{$\begin{array}{c}\text { Double stator topology (DSIPM) } \\
\text { Range of values }\end{array}$} \\
Parameter & Range of values & Parameter & $46^{\circ}, 48^{\circ}, 50^{\circ}, 52^{\circ}, 54^{\circ}$ \\
$W_{s}^{\circ}$ & $54^{\circ}, 52^{\circ}, 50^{\circ}, 48^{\circ}, 46^{\circ}$ & $W_{\text {os }}{ }^{\circ}$ & $46^{\circ}, 48^{\circ}, 50^{\circ}, 52^{\circ}, 54^{\circ}$ \\
$W_{r}^{\circ}$ & $54^{\circ}, 52^{\circ}, 50^{\circ}, 48^{\circ}, 46^{\circ}$ & $W_{\text {is }}$ & $W_{\text {or }}{ }^{\circ}$ \\
$H_{\text {spt }}(\mathrm{mm})$ & $0.5,1.0,1.5,2.0,2.5$ & $W_{\text {ir }}{ }^{\circ}$ & $48^{\circ}, 50^{\circ}, 52^{\circ}, 54^{\circ}$ \\
$H_{\text {sps }}(\mathrm{mm})$ & 2.5 & $H_{\text {ospt }}(\mathrm{mm})$ & $46^{\circ}, 48^{\circ}, 50^{\circ}, 52^{\circ}, 54^{\circ}$ \\
$H_{\text {rth }}(\mathrm{mm})$ & $0.5,1.0,1.5$ & $H_{\text {osps }}(\mathrm{mm})$ & $0.5,1.0,1.5$ \\
- & - & $H_{\text {ispt }}(\mathrm{mm})$ & $0.5,1.0,1.5$ \\
- & - & $H_{\text {isps }}(\mathrm{mm})$ & $0.5,1.0,1.5$ \\
- & - & & $0.5,1.0,1.5$ \\
\hline
\end{tabular}

magnetic circuit structure. Table 5 shows the values of $T_{m}$, $T_{c}, T_{f}$, and THD for each evaluation type. With respect to the choice on the minimum THD evaluation type of SSIPM the values of $T_{m}, T_{c}, T_{f}$, and THD are $0.97 \mathrm{Nm}$, $0.008 \mathrm{Nm}, 0.566 \mathrm{Nm}$, and $57.88 \%$, respectively. For double stator topology, the selections of min. THD evaluation type of DSIPM for values of $T_{m}, T_{c}, T_{f}$, and THD are $1.308 \mathrm{Nm}$, $0.0120 \mathrm{Nm}, 0.648 \mathrm{Nm}$, and $91.77 \%$, respectively. Meanwhile, for selection of min. THD evaluation types of DS thin pole shoe for values of $T_{m}, T_{c}, T_{f}$, and THD are $1.0454 \mathrm{Nm}$, 
TABLE 4: Selection of $\min$. THD, $\max . T_{f}$, $\max . T_{m}$, and $\min . T_{c}$ based on evaluation type.

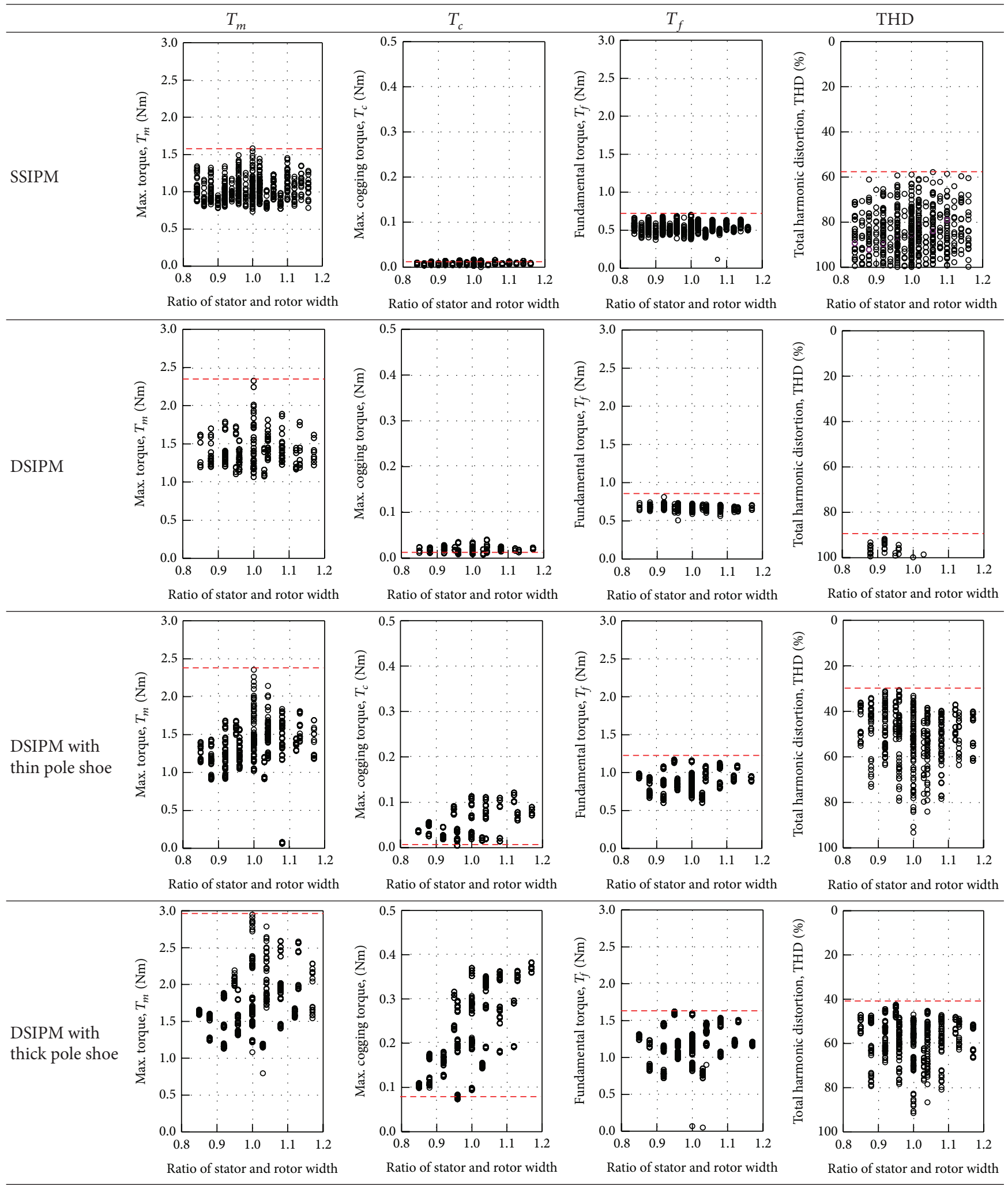




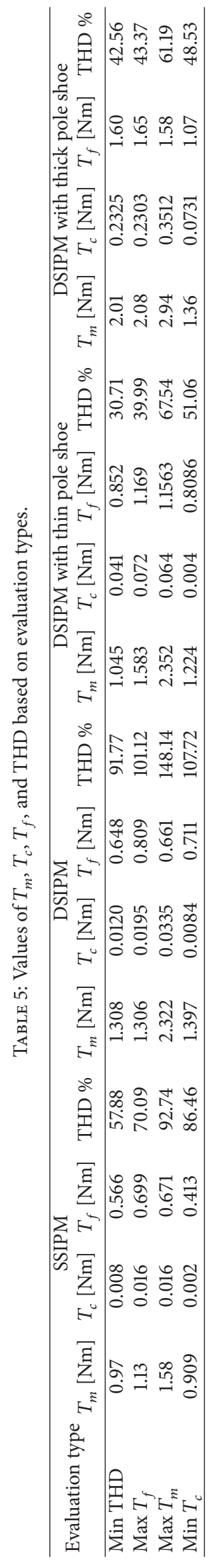




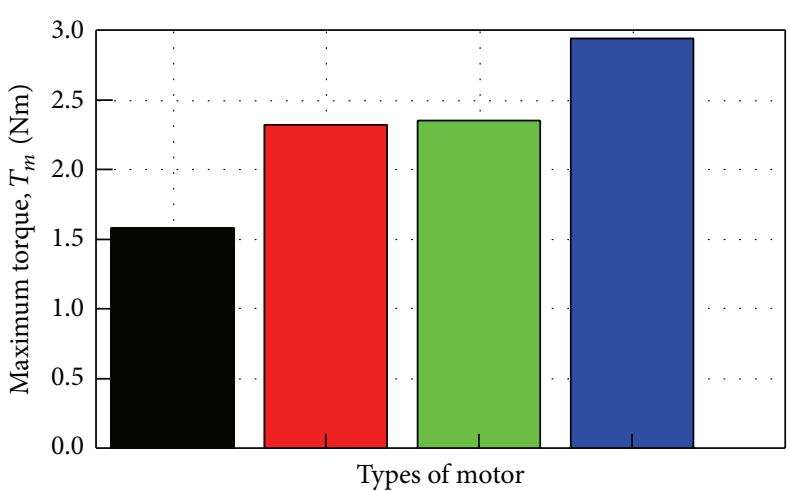

(a)

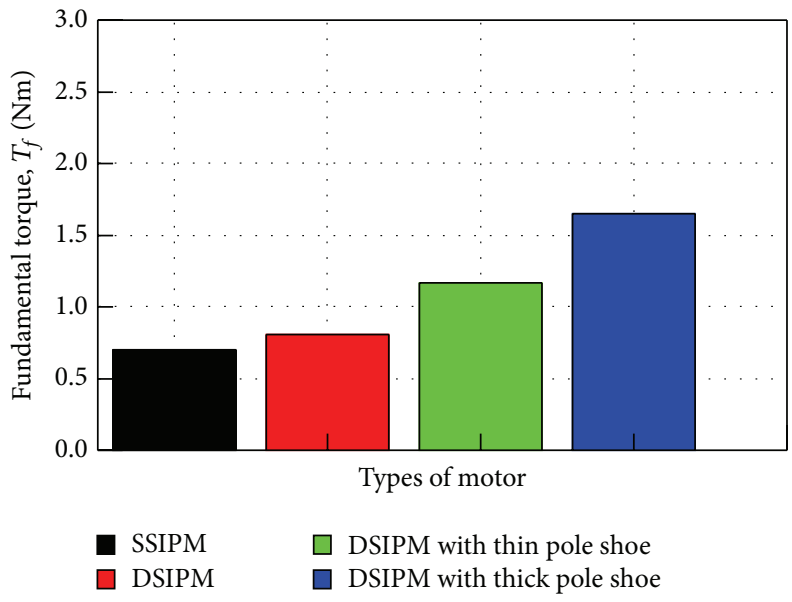

(c)

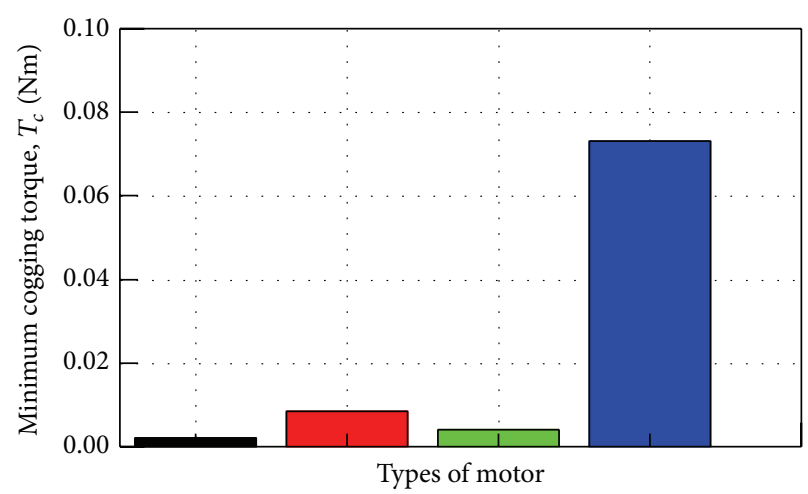

(b)

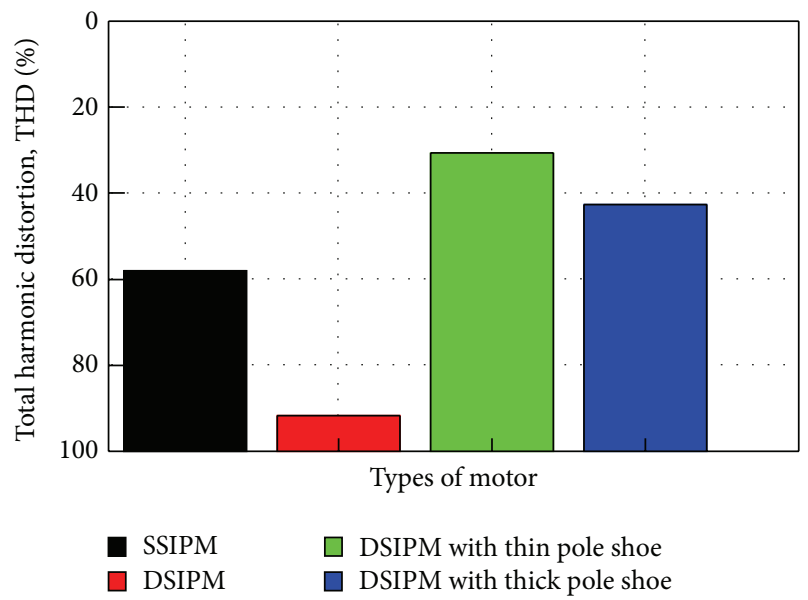

(d)

Figure 9: Choice on the best fit value of $T_{m}, T_{c}, T_{f}$, and THD. (a) Maximum torque; (b) minimum cogging torque; (c) fundamental torque; (d) total harmonic distortion.

$0.041 \mathrm{Nm}, 0.852 \mathrm{Nm}$, and $30.71 \%$, respectively. Selections of min. THD evaluation type of DS thick pole shoe for values of $T_{m}, T_{c}, T_{f}$, and THD are $2.0172 \mathrm{Nm}, 0.11769 \mathrm{Nm}, 1.6045 \mathrm{Nm}$, and $42.56 \%$, respectively. For value of $T_{m}$, the DS thick pole shoe produced the highest $T_{m}$ of $3.0 \mathrm{Nm}$ with higher cogging torque $0.38 \mathrm{Nm}$, respectively. The average of $T_{f}$ in DSIPM is approximately $0.7 \mathrm{Nm}$ and increases up to an average of $1.0 \mathrm{Nm}$ in DS thin pole shoe while $1.5 \mathrm{Nm}$ in DSIPM with thick pole shoe. This shows that DSIPM with thick pole shoe produces better result of torque component. It can be seen that the range of THD value is from $91 \%$ compared to that of the DSIPM, whereas for DS thin pole shoe it is from $30 \%$ to $90 \%$. For DSIPM with thick pole shoe, the range of THD value is from $40 \%$ to $90 \%$. The optimal value is selected (as shown by red line) to indicate the improvement of each model. The fabricated SSIPM is with the best fit that exhibits performance with the choice of minimum THD.

Figure 9 shows the optimum value of $T_{m}, T_{c}, T_{f}$, and THD as indicated by red lines of Table 5 . It can be seen that the optimal of max. $T_{m}$ is increased for each proposed magnetic circuit topology. Figure 9(a) shows that the maximum torque is achieved with the magnetic circuit improvements, with reduced cogging torque as seen in Figure 9(b). But for the DSIPM and DSIPM with thin pole shoe the cogging torque is reduced but the harmonic content is increased that would eventually reduce the average torque. The DSIPM with thick pole shoe exhibits reduced harmonic content deriving higher average torque along with the maximum torque. Each of the proposed magnetic circuit developed produces significant increment in terms of $T_{m}, T_{c}, T_{f}$, and decrement of THD but the choice on the torque density makes the DS thick pole shoe a better choice due to its better fundamental torque with reduced THD.

4.2. Experimental Evaluations. The fabricated best fit DSIPM with thick pole shoe for the same size and volume as that of the fabricated SSIPM is as shown in Figure 10.

The equipment arrangement for static torque measurement setup is shown in Figure 11. The fabricated motor is attached to a jig. An encoder is attached to the body of gear in order to detect the rotor position when the gear is rotated. The encoder is attached to Lab View in computer that received a signal from Data Acquisition Card. The purpose of gear is to extend the rotation time of the pulley so that smaller degree rotation can be achieved. As the pulley is rotated manually, the gear rotates in the common shaft of torque sensor and of the developed motor. The developed motor is being applied 


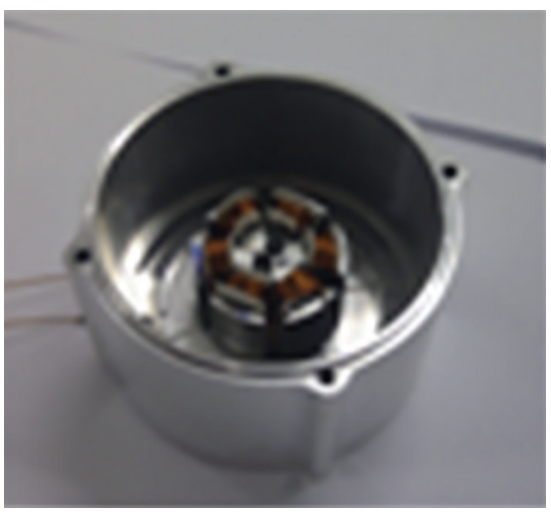

(a)

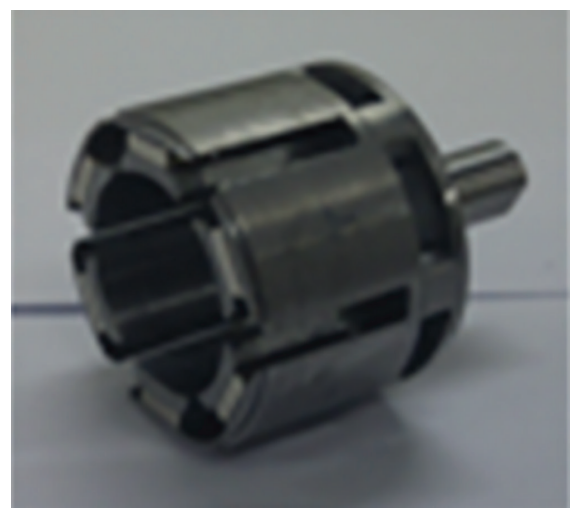

(b)

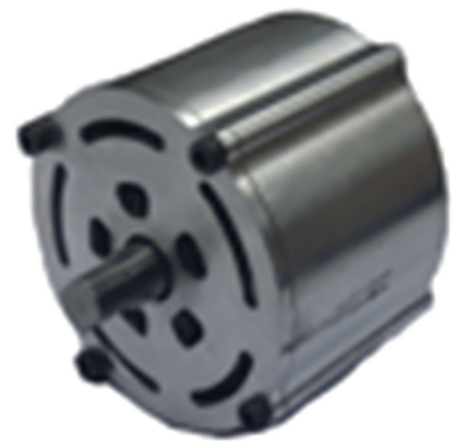

(c)

FIGURE 10: Fabricated best fit DSIPM with thick pole shoe motor. (a) Inner coil; (b) rotor; (c) assembled structure.

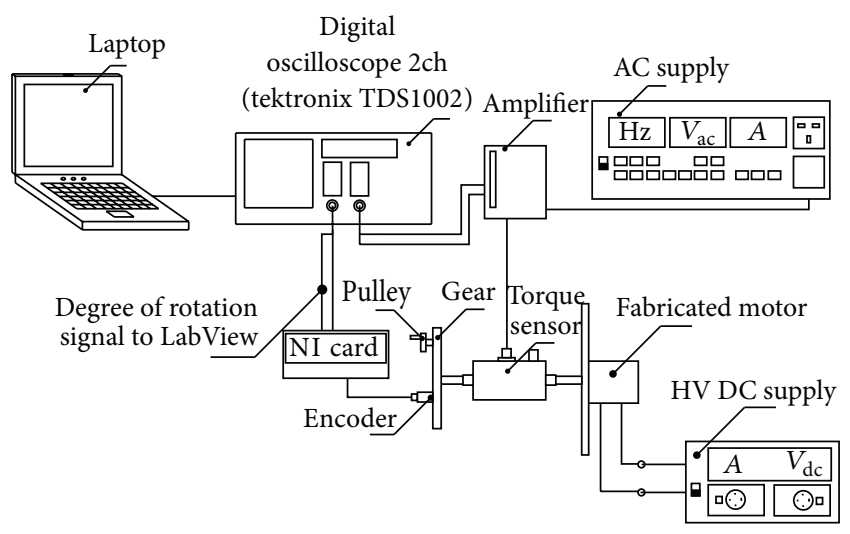

(a)

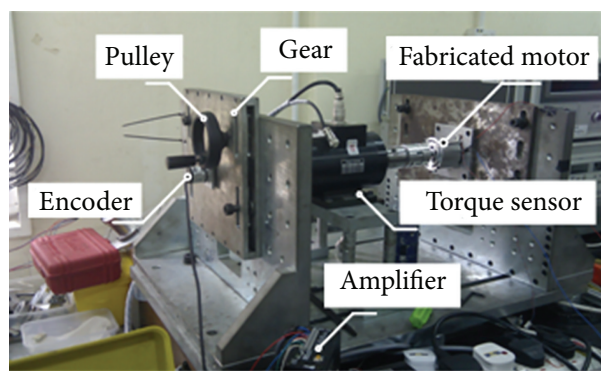

(b)

FIGURE 11: Equipment setup for torque measurement. (a) Block representation; (b) experimental setup.

by a DC current to match the similar value of NI that was calculated in the FEA. As a result, the static torque is plotted along the rotor position in degree for one pitch positioning of $120^{\circ}$. The measurement is varied from 0 At to $480 \mathrm{At}$.

4.3. Comparative Evaluations. Figure 12 shows comparison on torque characteristics of fabricated and simulated (FEA) of SSIPM and DSIPM with thick pole shoe. Results of fabricated SSIPM and DSIPM with thick pole shoe are in good agreement with the measurement result. It can be seen that the percentage error between simulation and measurement is less than $10 \%$.

For final comparison, motor constant square density $G$ is used to quantify the level of performance. The motor constant square density has considered the torque, power, and volume of a particular motor which is good for comparison purposes. The motor constant square density can be expressed as

$$
G=\frac{\left(K_{m}\right)^{2}}{V} \quad\left[\mathrm{Nm}^{2} \mathrm{~A}^{2} / \mathrm{W} / \mathrm{m}^{3}\right]
$$

where $K_{m}$ is the motor constant in $\left[\mathrm{Nm} / \mathrm{A} / \mathrm{W}^{(1 / 2)}\right], V$ is the volume of the overall motor $\left[\mathrm{m}^{3}\right]$. Table 6 shows the district comparative evaluations for all motors that had been developed in this research. It is evaluated that DSIPM with thick pole shoe is the best fit that is investigated with bigger $G$ value of 15 .

\section{Conclusions}

Interior permanent magnet single phase motor based on improvement of magnetic circuit is comprehensively investigated. The torque components for the various proposed magnetic topology are designed and compared to derive the best structure. The optimal parameters value is derived based on analysis using FEA. The fundamental torque for the best fit DSIPM with thick pole shoe exhibits double the torque value compared to conventional magnetic circuit due to the series magnetic circuit. The motor constant square density shows a performance improvement of $85.5 \%$ for the best fit DSIPM with thick pole shoe better compared to the conventional magnetic circuit of the SSIPM. The proposed magnetic circuit structure is fabricated and experimentally evaluated.

\section{Conflict of Interests}

The authors declare that there is no conflict of interests regarding the publishing of this paper. 


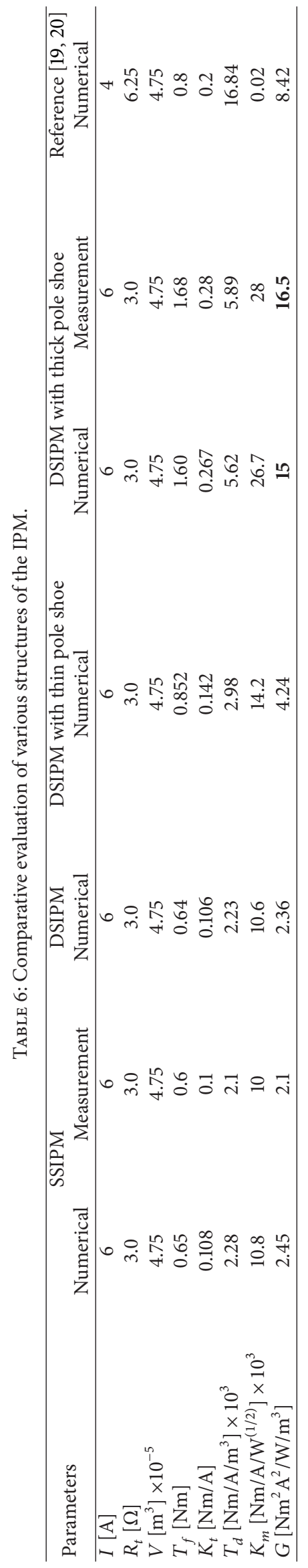




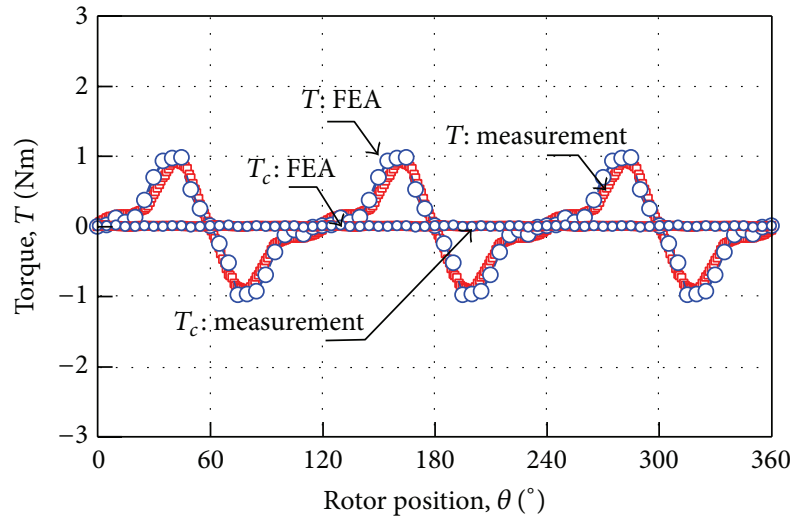

(a)

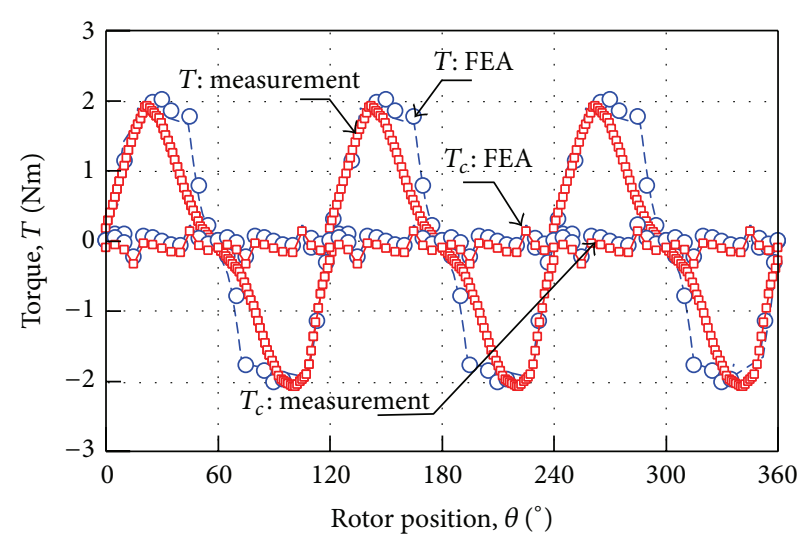

(b)

FIGURE 12: Measurement characteristics of the fabricated motor (a) SSIPM with thick pole shoe. (b) DSIPM with thick pole shoe.

\section{References}

[1] S. Bentouati, Z. Q. Zhu, and D. Howe, "Influence of design parameters on the starting torque of a single-phase PM brushless DC motor," IEEE Transactions on Magnetics, vol. 36, no. 5, pp. 3533-3536, 2000.

[2] S. Lizhi, F. Qi, and S. Jing, "Drive of single-phase brushless DC motors based on torque analysis," IEEE Transactions on Magnetics, vol. 43, no. 1, pp. 46-50, 2007.

[3] W. Wang, H. Wang, and H. R. Karimi, "Study on the characteristics of electromagnetic noise of axial flux permanent magnet synchronous motor," Abstract and Applied Analysis, vol. 2014, Article ID 764105, 8 pages, 2014.

[4] C. P. Liu, T. K. Lin, Y. H. Chang et al., "Performance of a single-phase DC brushless motor utilizing the ferromagnetic base material," Journal of Magnetism and Magnetic Materials, vol. 209, no. 1-3, pp. 176-179, 2000.

[5] B. Singh and S. Singh, "State of the art on permanent magnet brushless DC motor drives," Journal of Power Electronics, vol. 9, no. 1, pp. 1-17, 2009.

[6] H. B. Ertan, B. Dağ, and G.-A. Capolino, "Calculation of parameters of single-phase PM motor for design optimization," IEEE Transactions on Energy Conversion, vol. 20, no. 3, pp. 538-548, 2005.

[7] M. Norhisam, K. Alias, R. N. Firdaus, S. Mahmod, N. Mariun, and J. Abdul Razak, "Comparison on thrust characteristic of linear oscillatory actuators," in Proceedings of the IEEE International Conference on Power and Energy, pp. 470-475, Kuala Lumpur, Malaysia, November 2006.

[8] R. N. Firdaus, M. Norhisam, N. Mariun, I. Aris, M. Nirei, and H. Wakiwaka, "Torque characteristics of single phase brushless $\mathrm{dc}$ permanent magnet motor," Journal of the Japan Society of Applied Electromagnetic and Mechanics, vol. 19, pp. S95-S98, 2011.

[9] C. C. Hwang, C. M. Chang, S. P. Cheng, C. K. Chan, C. T. Pan, and T. Y. Chang, "Comparison of performances between IPM and SPM motors with rotor eccentricity," Journal of Magnetism and Magnetic Materials, vol. 282, no. 1-3, pp. 360-363, 2004.

[10] T. J. Kim, S. M. Hwang, K. T. Kim, W. B. Jung, and C. U. Kim, "Comparison of dynamic responses for IPM and SPM motors by considering mechanical and magnetic coupling," IEEE Transactions on Magnetics, vol. 37, no. 4, pp. 2818-2820, 2001.
[11] C. Feng, X. Jing, G. Bin, C. Shukang, and Z. Jiange, "Doublestator permanent magnet synchronous in-wheel motor for hybrid electric drive system," IEEE Transactions on Magnetics, vol. 45, no. 1, pp. 278-281, 2009.

[12] Y. Wang, M. Cheng, M. Chen, Y. Du, and K. T. Chau, "Design of high torque density double stator permanent brushless motors," IEEE Transactions on Magnetics, vol. 5, no. 3, 313327 pages, 2010.

[13] S. Niu, K. T. Chau, J. Li, and W. Li, "Eddy-current analysis of double-stator inset-type permanent magnet brushless machines," IEEE Transactions on Applied Superconductivity, vol. 20, no. 3, pp. 1097-1101, 2010.

[14] M. Norhisam, S. Ridzuan, R. N. Firdaus, C. V. Aravind, H. Wakiwaka, and M. Nirei, "Comparative evaluation on power speed density of portable permanent magnet generator for agricultural application," Progress in Electromagnetics Research, vol. 129, pp. 345-363, 2012.

[15] M. Norhisam, M. Norafiza, M. Shafiq et al., "Design and analysis of slot type embedded permanent magnet generator," Journal of Industrial Technology, vol. 18, no. 1, pp. 1-14, 2009.

[16] G. H. Kang, J. Hur, H. G. Sung, and J. P. Hong, "Optimal design of spoke type bldc motor considering irreversible demagnetization of permanent magnet," in Proceedings of the 6th International Conference on Electrical Machines and Systems, pp. 234-237, 2003.

[17] D. Lin, P. Zhou, and Z. J. Cendes, "Analytical prediction of cogging torque in spoke type permanent magnet motors," in Proceedings of the International Conference on Electrical Machines, pp. 1-5, September 2008.

[18] K. Boughrara, R. Ibtiouen, and T. Lubin, "Analytical prediction of magnetic field in parallel double excitation and spoke-type permanent-magnet machines accounting for tooth-tips and shape of polar pieces," IEEE Transactions on Magnetics, vol. 48, no. 7, pp. 2121-2137, 2012.

[19] S. Ahmed and P. Lefley, "Study of the impact of asymmetrical stator pole arc on the cogging torque for single phase permanent magnet BLDC motor," in Proceedings of the International Conference on Electric Power and Energy Conversion Systems, pp. 1-4, November 2009.

[20] S. Ahmed, Investigations into the improvement of a single phase permanent magnet brushless dc motor [Ph.D. thesis], University of Leicester, 2011. 
[21] C. V. Aravind, M. Norhisam, I. Aris, M. H. Marhaban, and M. Nirei, "Electromagnetic design and FEM analysis of a novel dual air-gap reluctance Machine," Progress in Electromagnetic Research, vol. 140, no. 5, pp. 523-544, 2013.

[22] C. A. Vaithilingam, M. Norhisam, M. R. Zare, I. Aris, and M. H. Marhaban, "Computation of electromagnetic torque in a double rotor switched reluctance motor using energy methods," Energies, vol. 5, pp. 4008-4026, 2012.

[23] R. N. Firdaus, Improvement of magnetic circuit for development of high torque density single phase brushless DC permanent magnet motor [Ph.D. thesis], University Putra Malaysia, 2013.

[24] A. Kameari, "Local force calculation in 3D FEM with edge elements," International journal of applied electromagnetics in materials, vol. 3, no. 4, pp. 231-240, 1993. 


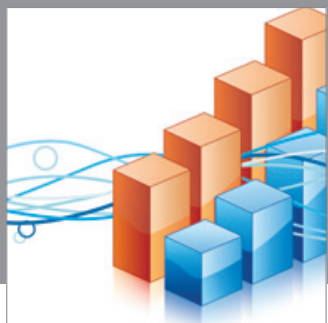

Advances in

Operations Research

mansans

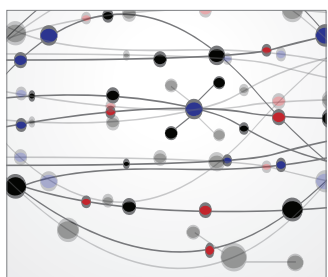

The Scientific World Journal
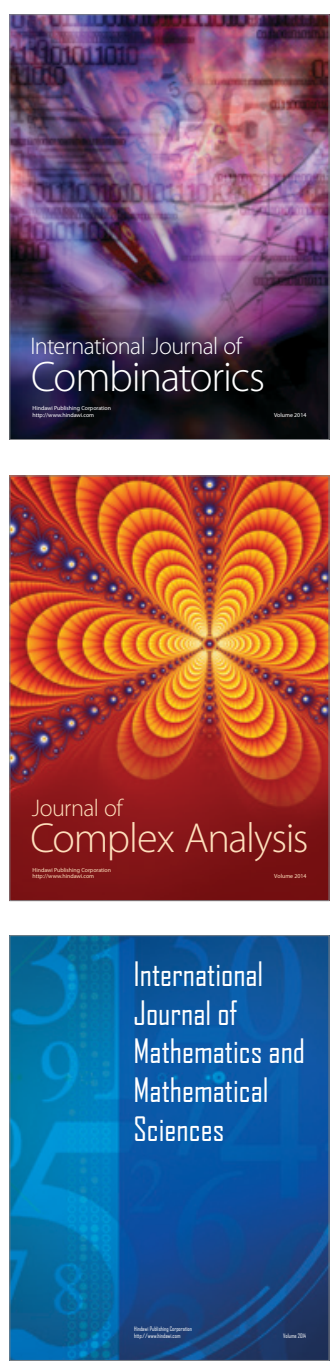
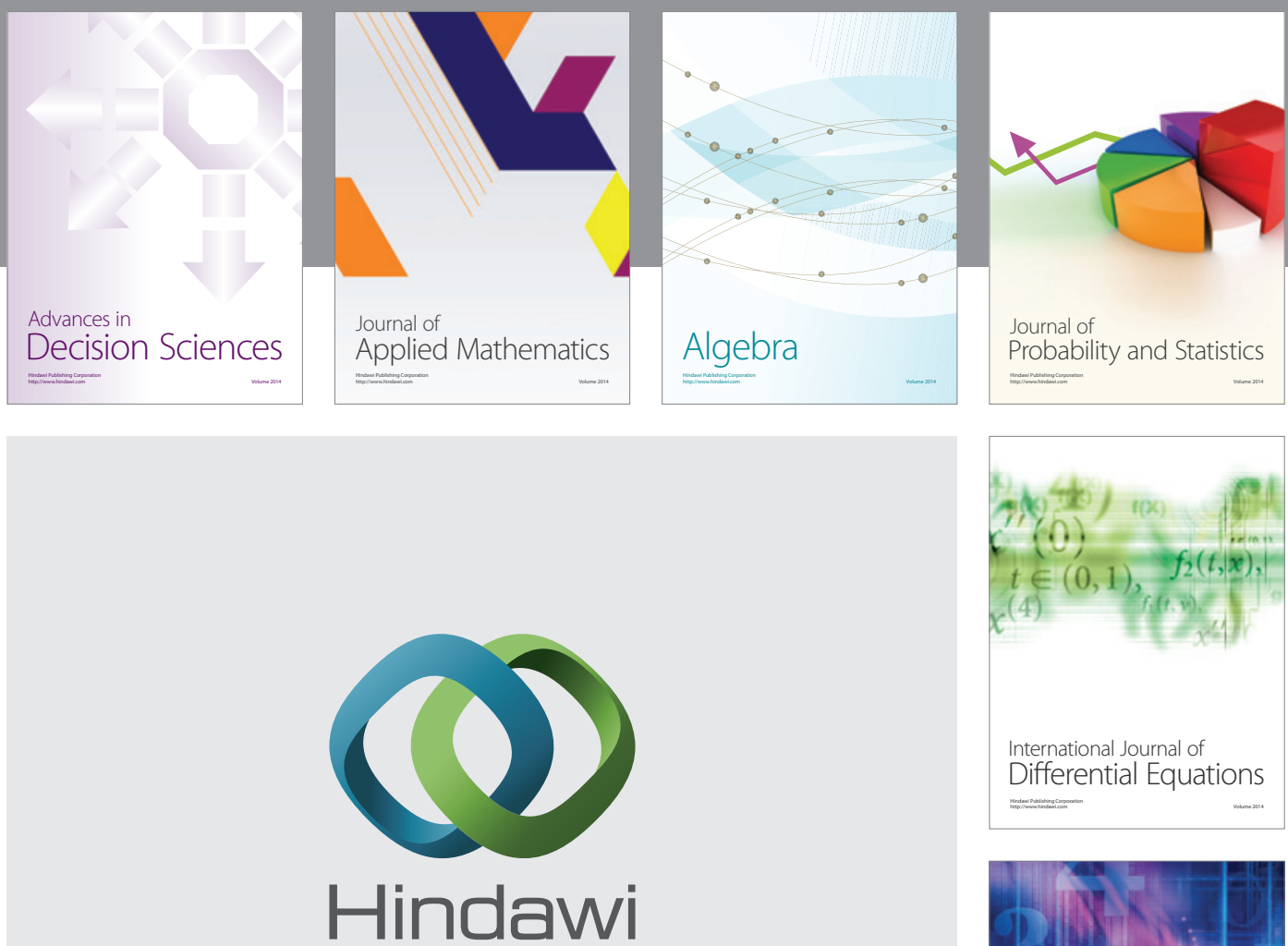

Submit your manuscripts at http://www.hindawi.com
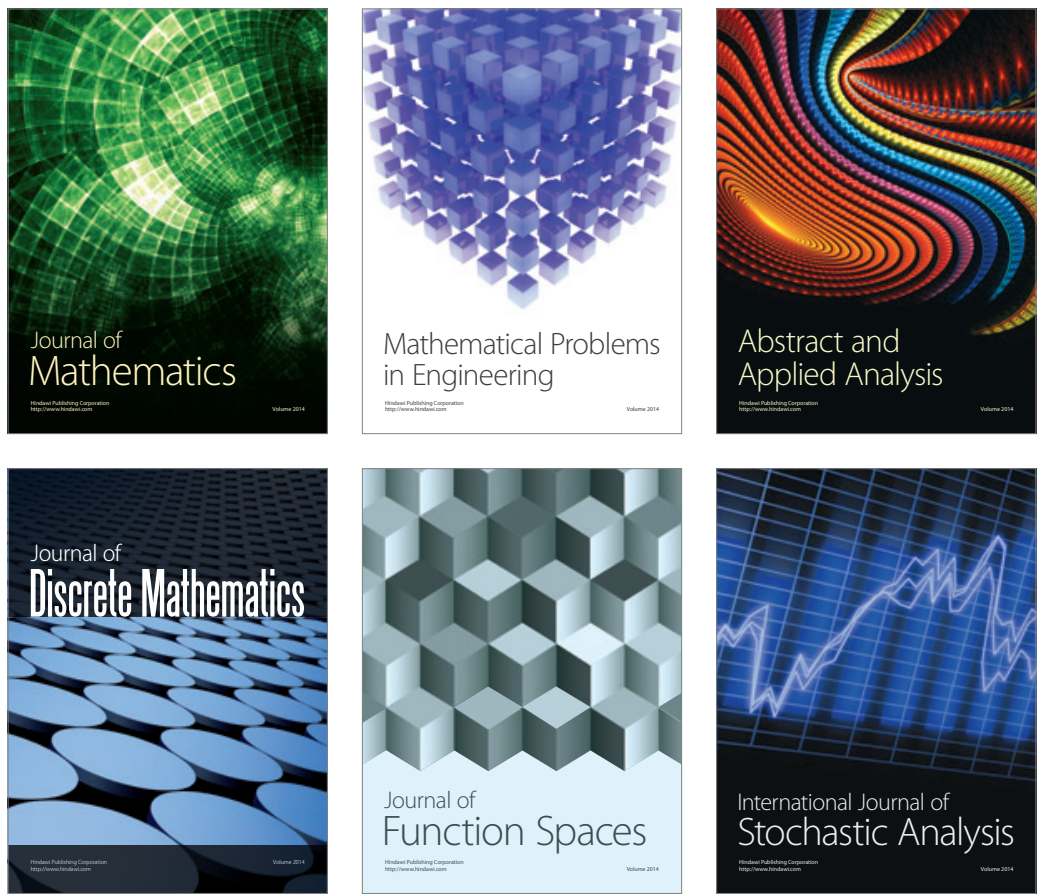

Journal of

Function Spaces

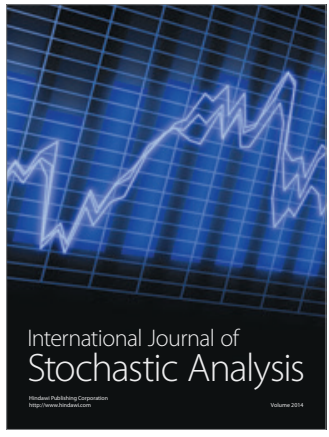

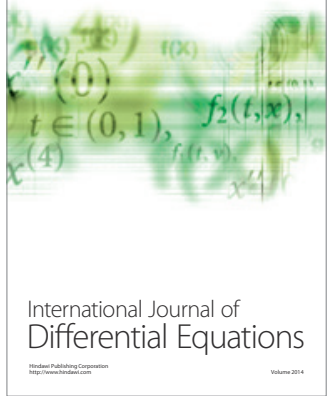
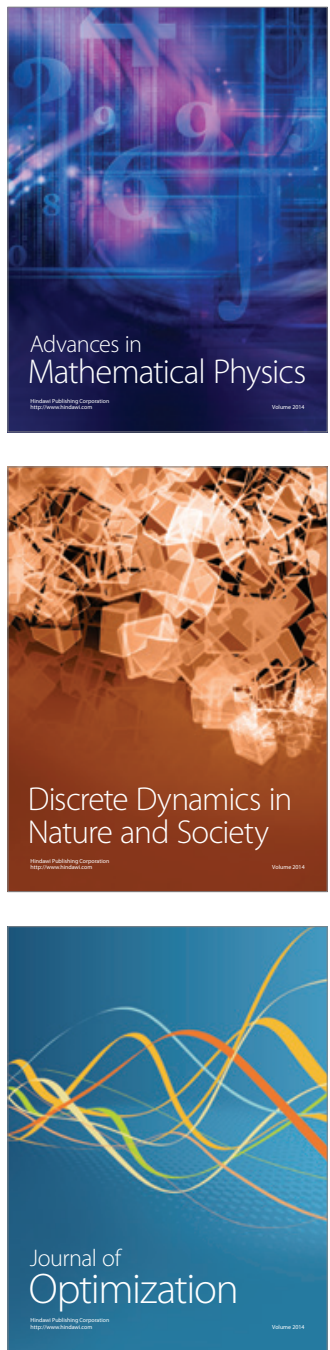